\title{
La convulsión financiera del Perú y la liquidación del Banco Perú y Londres de 1925-1931
}

\author{
Âlvaro Lipa Sinche \\ HAVANA_CLUBX@hotmail.com \\ Universidad Nacional Federico Villarreal
}

\section{RESUMEN:}

El presente estudio analiza la correlación de la convulsión financiera, determinada por la caída en el precio de las exportaciones, el fenómeno del niño de 1925 y la intervención gubernamental a través de instituciones de fomento, además de los antecedentes de la liquidación del Banco Perú y Londres y el excesivo flujo de créditos colocados hacia la agro exportación. Por lo tanto se le pondrá atención al resultado ascendente del crédito agrícola, mediante la utilización de cuadros estadísticos e informes bancarios en un nivel desagregado complementando así el análisis cuantitativo. Finalmente el artículo tiende a analizar el estudio de las oscilaciones y condiciones cambiarias de los activos del Banco Perú y Londres que mediante las actas de directorio y las memorias del banco dejan explicar el contexto de su liquidación. Este estudio es la primera aproximación que evalúa la eficiencia financiera del crédito agrícola, en este sentido la información financiera de los archivos otorga un rico análisis para el desarrollo de su historia.

Palabras Clave: Banco Perú y Londres; Política financiera; Crédito agrícola; Estabilización Monetaria; Banco Hipotecario y de Crédito agrícola.

\section{The financial convulsion and the liquidation of the Peru and London Bank of 1925-1931}

\begin{abstract}
:
The present study analyzes the correlation of the financial convulsion, determined by the fall in the price of exports, the phenomenon of the child of 1925 and the government intervention through fomentation institutions, with the antecedents of the liquidation of Bank Peru and London Through the excessive flow of credits placed to the agro export. Therefore, the upward result of agricultural credit will be focused on the use of statistics and bank reports at a disaggregated level, complementing the quantitative analysis. This led to the finding of fluctuations and exchange-rate conditions for the assets of Peru and London, which, through the minutes and the bank's reports, explain the context of their liquidation. This study is the first approach that evaluates the financial efficiency of agricultural credit, in this sense the financial information of the archives provides a rich analysis for the development of its history.

Keywords: Peru and London Bank; Financial Policy; Agricultural Credit; Monetary Stabilization; Mortgage Bank and Agricultural Credit.
\end{abstract}

(C) Los autores. Este artículo es publicado por ISHRA, Revista del Instituto Seminario de Historia Rural Andina de la Facultad de Ciencias Sociales de la Universidad Nacional Mayor de San Marcos. Este es un artículo de acceso abierto, distribuido bajo los términos de la licencia Creative Commons Atribucion - No Comercia Compartir Igual 4.0 Internacional. (http://creativecommons.org/licenses/by-nc-sa/4.0/) que permite el uso no comercial, distribución y reproducción en cualquier medio, siempre que la obra original sea debidamente citada. 


\section{Introducción}

Esta investigación relaciona la especialización del crédito agrícola para el sector agroexportador y del declive de sus activos, como también las graves faltas de cálculo en sus activos financieros que experimentó el Banco Perú y Londres en el periodo de 1925 a 1930.

Como antecedente de la creación del Banco Perú y Londres, se tiene la sección hipotecaria del Banco del Callao. Esta fue atractiva a la London Bank, que lo consideró una institución estratégica para aprovechar la fusión de capitales, los que propiciarían condiciones favorables para la inversión extranjera después de la guerra del Pacífico. Por esta razón se crea el Banco Perú y Londres que había aceptado la inversión extranjera en una proporción de 8000 acciones frente a los 12000 proveniente del Banco del Callao. Y es así que se constituye el capital bancario con 200 mil Libras Peruanas. (Quiroz, 1989).

El objetivo de la combinación fue traer capital extranjero a fin de monopolizar el negocio hipotecario y crediticio en Lima, reduciendo para este fin la tasa de interés del 8 al $6 \%$ anual. Cabe mencionar que la composición del negocio hipotecario y crediticio contaba con la participación de la Sociètè Gènèrale y el Banco de París representados por el Anglo South American Bank a través del Banco Perú y Londres, que en su conjunto representaban el Credit Foncier Peruvien, es decir la sección hipotecaria y crediticia del banco, con un capital inicial de 337,000 francos (Banco Perú y Londres, Directorio, 1912, vol.6).

De esta manera se instauró la dirección francesa en el banco que llevó a que las decisiones más importantes de la política financiera de la institución fueran tomadas en París, ya que después del establecimiento del Credit Foncier Peruvien, El Banco de Paris adelantó $12 ` 500,000$ de francos a ser pagados en 37 años a favor del Banco Perú y Londres. Por otra parte el Credit Foncier Peruvien habia adquirido la totalidad de los créditos hipotecarios del Banco Perú y Londres. Posteriormente se adquirió del Banco de París 500 mil francos más que representaban una cifra por encima del préstamo otorgado para la compra de acciones en el Perú. (Inspección Fiscal de Bancos, 1913, p.190).

Por lo tanto el Banco Perú y Londres va a ser un agente interesado en mantener los precios de exportación y los costos internos, llegando a establecer la tasa de descuento en $7.5 \%$, logrando de esta manera la monopolización de las letras de cambio, interviniendo así en las oscilaciones de la Libra Peruana. Como respuesta a la actitud monopolista de la banca privada se va a crear una institución oficial llamada la Junta de Vigilancia, que tenía entre sus funciones controlar las emisiones de los bancos privados y centralizar sus garantías de oro ya que hasta el momento la banca privada tenía excesiva ventaja que llevaba a peligrosos ciclos inflacionarios. La consecuencia de esta política intervencionista fue la limitada emisión; lo cual forzó a restringir y cerrar el crédito hasta inicios de la década de 1920. (Banco Perú y Londres, Directorio, 1914, Vol. 8).

Sin embargo hasta antes de acabada la Primera guerra mundial el crédito agrícola no había sido mayoritario. Con lo cual el banco mantenía solo algunos intereses agrícolas, siendo el más importante la administración de la Hacienda San José, que fuera vendida a la British Sugar Co. Además en un afán de aumentar las reservas líquidas del banco, este realizó otra liquidación agrícola apresurada y extemporánea de los activos a través de la venta de su participación del $67.5 \%$ de la hacienda Palpa, su Ferrocarril y el Muelle de Chancay al terrateniente Miguel Gallo por 85’000 Libras Peruanas en 1917 (Banco Perú y Londres, Directorio, 1917 Vol.9). 
En el contexto de la Primera guerra mundial, las condiciones del acceso al crédito comercial estuvieron restringidas a los productores.

El Mercantile Bank of America de New York, tenía como finalidad ayudar a la exportación a los Estados Unidos, sin embargo el crédito estaba restringido, y solamente se determinó a proteger sus fondos en oro e inversiones de valores, estableciendo una tasa de cambio que llegó a cotizar a la Libra Inglesa en un 21\% por encima de la Libra Peruana. Con lo cual los depósitos bancarios no cesaron en disminuir, reduciendo así el crédito bancario. Este contexto junto con la liquidación del Banco Alemán Transatlántico hacia el final de la Primera Guerra Mundial, explican la lenta recuperación de los activos totales de la banca privada a pesar de las ganancias que las exportaciones experimentaron en este periodo (Banco Perú y Londres, Directorio, 1918, Vol.1, p.91).

En 1921 mediante las políticas financieras del Presidente Augusto B. Leguía, la dirección extranjera del Credit Foncier Peruvien decide retirarse, con lo cual la dirección nacional del Banco Perú y Londres asumió los activos y pasivos de la sección crediticia, en los años siguientes el banco va a iniciar una política financiera de expansión del crédito a fin de canalizar las exportaciones de materia prima (Banco Popular, Sección Hipotecaria, 1920).

Por lo tanto se va a establecer una relación más directa entre la banca privada y los agroexportadores, asumiendo así comisiones comerciales exclusivas, como la apertura de la cuenta bancaria «custodia y garantía» para los préstamos sobre la producción de azúcar y algodón.

Estas politicas fueron un paso definitivo en la autonomía financiera de la elite nacional; la cuenta bancaria consistía en que los agroexportadores negociaban en moneda representada en oro, pero que no podían trasladar de los Estados Unidos por impedimentos legales. Por lo tanto el Banco Perú y Londres entre 1920 y 1925 se dedicó a especializar sus créditos asignando el $34 \%$ a la agricultura comercial $32 \%$ al comercio y $12 \%$ a instituciones gubernamentales (Quiroz, 1989, p.139).

Sin embargo, la constante inflación resultado del incremento en los costos de producción más los costos de importación y la subida general de los precios, llevaron a un descenso del valor interno de la Libra Peruana. Esto se reflejó en la abundancia de letras de cambio en el extranjero, sobrevaluando así la tasa de cambio, debido a que el oro de los agroexportadores en el extranjero no podía ser usado, con lo cual se quedaban sus activos en el exterior, mientras que los precios iban en aumento los agroexportadores por su parte demandaban incrementos en la emisión de billetes respaldado por el oro de fondos nacionales mantenidos en los Estados Unidos. Este fue el conflicto entre banqueros y agroexportadores en la década de 1920.

En ese contexto en marzo de 1920 el Anglo South American Bank, de composición británica empezó a vender sus acciones del Banco Perú y Londres por un total del 20\% del capital del banco, con la intención de retornar a Inglaterra y negociar con el tipo de cambio en declive, con lo cual siguió un retiro de fondos de inversionistas extranjeros. Esta fuga de capitales tuvo su repercusión en la composición social de los accionistas del banco.

Hasta la reunión de la Junta de Accionistas en marzo de 1920 los extranjeros representaron el $71 \%$, pero un año después solo formaban un 34\%. Por lo tanto los más importantes inversionistas extranjeros del Banco Perú y Londres fueron remplazados por agroexportadores que compraron parte sustancial de las acciones, como Antero Aspillaga quien poseía 3,190 acciones de un total de 22,328 en 1922, también se incrementó con 
otro principales accionistas entre ellos, Mansueto Canaval, Demetrio Olavegoya, Alfredo Ferreyros entre otros (Banco Perú y Londres, 1921, Accionistas; Vol.3, p.25).

La estructura financiera del Banco Perú y Londres cambió significativamente después de la instalación del Banco de Reserva del Perú en 1922. La elite nacional exportadora se manifestó a favor de las oportunidades del crédito, que abrió la expansión del comercio en especial para los productores de azúcar y algodón. Además los exportadores necesitaban crédito para salir de la contracción de 1921.

Por lo tanto el Banco Perú y Londres en su afán de especialización en los créditos de exportación solicitó un préstamo externo al Comptoir National d'Escompte de Paris y a los agentes Brancker, Boxwell \& Co. de Liverpool, adquiriendo así activos financieros por un total de 392,874 Libras Peruanas con lo cual se aperturó una política de crédito para los asuntos agrícolas, compitiendo de esta manera con el Mercantile Bank of América (Banco Perú y Londres, 1922, Directorio, Vol.13, p.15).

Los agroexportadores no solo tuvieron una presencia estratégica en el Banco Perú y Londres sino también en el Banco de Reserva del Perú, permitiendo la expansión del crédito y estandarizando la flexibilización de la moneda, estas medidas favorecieron los intereses financieros de los agroexportadores. «Por otra parte se implanta una estabilización favorable para la obtención de préstamos y es así que en 1922, se van aplicar medidas para estabilizar el tipo de cambio de \$3.82 por Libra peruana con la finalidad de negociar con acreedores norteamericanos» (BRP, Legislaciones, 1944, p.7).

El Banco Perú y Londres en este sentido utilizó sus contactos locales para proveer a los más importantes agroexportadores con beneficios excepcionales a fin de mantenerlos firmemente como clientes exclusivos. Promovió así la exclusividad en la compra de letras de cambio brindando tasas de intereses especiales a sus cuentas corrientes acreedoras de los grupos exportadores, como fue a la familia Chopitea (Hacienda Laredo), Víctor Larco (Hacienda Roma) Nicanor Carmona (cultivador de arroz), Muñoz Najar \& Hnos. en Arequipa, exportadores de lana. También el banco abre créditos en cuentas corrientes y préstamos hipotecarios garantizados por los stock de productos de sociedades agrícolas como Aspíllaga Hnos., Solar Hnos., Miguel Echenique, y otros exportadores principalmente de azúcar y algodón. Sobre los depósitos a largo plazo estos se incrementaron en 400,000 Libras Peruanas.

Con lo cual el otorgamiento del crédito fue un recurso que el Banco explotó eficazmente hasta el extremo de desplazar al Mercantile Bank sobre el dominio del mercado exportador. Sin embargo el Banco Perú y Londres estableció una peligrosa especialización en el financiamiento a los agroexportadores al expandir ampliamente el crédito (Quiroz, 1989, p.270).

Sobre los préstamos mayoritarios a los agroexportadores se tiene el caso del crédito en marzo de 1923 a la hacienda azucarera Roma de propiedad de Víctor Larco Herrera. «El Banco Perú y Londres otorgó la suma de 250 mil Libras Peruanas (10 veces más del capital que se necesitó para fundar el Banco de Trujillo en 1920). De los cuales 168,000 Libras peruanas se utilizaron para pagar viejas deudas. Al tener una fuerte inversión crediticia el Banco Perú y Londres consiguió el derecho de dirigir comercialmente los 700 mil quintales de azúcar anuales, que producía la hacienda Roma» (Banco Perú y Londres: Directorio, 1923, Vol. 13, $\mathrm{N}^{\mathrm{o}} 1457$, p. 270). 
Por otra parte, al tiempo que se favorecía a representantes del régimen de Augusto B. Leguía, el Banco Perú y Londres criticaba fuertemente la política económica; por ejemplo en el retiro de la compañía recaudadora de impuestos que había organizado el sistema impositivo desde 1913 y que incluso se ofrecía como garantía de préstamos en el extranjero (Cámara de diputados, 1921). Las conexiones del banco con instituciones extranjeras estuvieron listas para empezar una campaña diplomática internacional con el gobierno sin embargo la nueva dirección nacional frenó esta lucha.

El Banco Perú y Londres será afectado por el carácter de la estructura financiera establecido por el gobierno de Augusto B. Leguía, ya que se van realizar transacciones con firmas norteamericanas dominando así el financiamiento de obras viales y de urbanización, mediante los préstamos de las instituciones británicas como la Speyer \& Co. de Londres, que llevó incluso a impulsar medidas regulatorias en el gobierno, estableciendo requerimientos mínimos de capital y de inversión para los bancos en el país, por ejemplo: en 1925 se consideró la creación del Banco Industrial del Perú en relación a los acuerdos de la Foundation Company y la Guaranty Trust mediante la modificación de la ley hipotecaria que afectaba directamente al Banco Perú y Londres.

Desde mediados de la década del veinte, la política financiera va a promulgar atribuciones normativas reglamentando los depósitos de ahorro en los bancos, exonerándolos de todo impuesto. Posteriormente la Ley N 6161 de abril de 1928 va a disponer que el 50\% de los fondos provenientes del ahorro deberían ser invertidos en cédulas hipotecarias, o en bonos agrícolas. Meses después se va a inaugurar el Banco Central Hipotecario del Perú, logrado por un dilatado periodo de preparación en el que participaron banqueros norteamericanos como el Seligman \& Brother y las instituciones bancarias nacionales cuyas secciones hipotecarias habrían de ser traspasadas a la nueva entidad. Sin embargo, este nuevo banco no va tener la confianza como sí lo tenían los bancos privados.

Para 1929 el Banco Perú y Londres había monopolizado las actividades de la mayoría de los comerciantes, teniendo en funcionamiento 19 agencias provinciales y 4 distritales, además de participar de los capitales del Banco de Tacna (Chile) y el Banco de la Nación Boliviana, hasta el momento no había otra institución que tenga esa cobertura territorial. El Banco Italiano y el Banco Alemán juntos tenían 10 sucursales en todo el país. Sin embargo como ya había ocurrido con la quiebra del Mercantile Bank of América en 1924; la expansión territorial no evita la liquidación. En este sentido, el desarrollo de la estructura financiera peruana en provincias contribuyó a la concentración de activos financieros en el área centralista de Lima y Callao, que tenían aproximadamente el $80 \%$ de la cuentas de ahorro, seguido por Arequipa con un 9\% y Trujillo con 3\% (Inspección Fiscal de Bancos, Informe, 1926-1929).

En esta primera parte se ha expuesto la trayectoria financiera e institucional de los agentes económicos clave, en una contextualización histórica centralizada en el conocimiento del crédito hipotecario y agrícola anterior a los años de estudio de la investigación. Finalmente, el artículo propone la estructura expositiva en tres subtítulos, con la finalidad de lograr una consistencia en las exposiciones del debate sobre la liquidación del Banco Perú y Londres.

\section{El crédito agrícola en el Banco Perú y Londres}

El desarrollo nacional alcanzado por un país depende de la economía de producción relacionada con las instituciones financieras, siendo estas últimas decisivas ya que intervienen 
significativamente en los niveles monetarios y empresariales (Cameron, 1972). Por lo tanto la relación entre desarrollo financiero, y el crecimiento económico se van a traducir a un nivel técnico de cuantificación de los activos financieros. Según las investigaciones de Goldsmith concluye «que para las economías subdesarrolladas esta cuantificación tiene un bajo promedio, lo cual indica que no existe una institución que realice créditos a largo plazo y que la excepción se puede dar en agencias gubernamentales» (Goldsmith, 1969, p.8).

El desarrollo de los créditos agrícolas atravesó tres distintas fases. El primero de un moderado incremento de los créditos entre 1889 y 1907 que coindice con el periodo de la reconstrucción nacional, el segundo tiene un estancamiento desde 1907 hasta 1921, y el tercer periodo realiza una rápida expansión entre 1922 y 1929 que coincide con el boom de las agro-exportaciones. Por lo tanto existe una correlación de las fases de créditos y de desarrollo productivo del país así como los índices de crecimiento. Cabe explicar que la ley que reguló los créditos data de 1889 y solamente era útil para el otorgamiento de crédito a grandes propiedades de familias de agricultores que fueron los que accedieron al crédito entre 1890 hasta 1925. Lo cual significa que ni los pequeños propietarios cuya propiedad valiera menos de 2000 Libras Peruanas ni el agricultor que trabajara en una tierra alquilada podrían beneficiarse de los préstamos, por lo tanto el crédito tuvo poco impacto en los productores de pequeña escala explicando así el desarrollo hacia afuera de un mercado dependiente de la compra en el extranjero y de un estancamiento del mercado interno en su proceso de modernización regional.

Sobre los créditos otorgados, estos solo cubrían un corto plazo y eran aprobados de preferencia a aquellos que se dediquen al comercio exportador, y se usaban a través del instrumento financiero llamado «letra de cambio», sin embargo para la década del veinte se van a sistematizar y expandir los créditos para la exportación mediante el estímulo de la especialización y el financiamiento público, asegurando así la oferta de las letras de cambio que venían siendo disputadas, sobre todo por el Mercantile Bank of América de New York; que en el pasado el total de activos financieros disminuyeron en contraste con el incremento de las actividades crediticias del banco mencionado. Por lo tanto, con el tiempo el estímulo a la especialización, del negocio crediticio, del financiamiento público y a la importación de capital extranjero llegaron a ser actividades importantes para el Banco Perú y Londres (Quiroz, 1989, p.41).

Sin embargo la década del veinte inicia con la controversia de fijar la tasa de interés para el otorgamiento del crédito, por lo cual

El Banco Perú y Londres decidió elevar su tasa de interés en 1\%, mientras que el gobierno por resolución suprema estableció un tope máximo de interés del 10\% para las operaciones de préstamo y crédito, lo que motivó a cancelar todas las cuentas corrientes porque ya no serían rentables al existir un limitante. El gobierno entonces decidió aceptar la propuesta del Banco Perú y Londres pero extendiéndola mediante otra resolución, señalando las circunstancias anormales del mercado de dinero y de adolecer de falta de elasticidad, por lo tanto se fijaría la amortización en cuentas corrientes deudoras, es decir se estableció un limitante a su ingreso, teniendo como índice bajo el $21 \%$ en relación a las cuentas corrientes de préstamos y créditos (Banco Perú y Londres, Directorio, vol.12, 1921, p.156).

Al instaurarse el Banco de Reserva del Perú presidido por Eulogio Romero en 1922, se va a poner fin a esta controversia del crédito y de la tasa de descuentos; esto generó un giro positivo en el mercado crediticio. «los directores del Banco de Reserva del Perú van a reducir la 
tasa de descuentos sobre los créditos agrícolas en 6.5\%, otorgando así ventajas crediticias a los agroexportadores a través de emisión de bonos a sociedades agrícolas» (Banco Perú y Londres, Directorio, 1922, vol.13, p.151).

El porcentaje del crédito otorgado por el Banco Perú y Londres para el sector agrícola va a registrar un nivel sin precedentes de $27 \%$ del total de créditos, superando al crédito comercial que constituyó un 25\%, y del gobierno peruano en 21\% para el mismo periodo, esto se realizó mediante una tasa de interés anual de 8 a 10\%, con lo cual el capital crediticio fue la herramienta financiera que desarrolló la economía nacional y a la elite nativa.

Los créditos otorgados van a tener una línea ascendente que inicia con 75,000 Libras Peruanas a inicio de la década del veinte, consolidándose de esta manera como instrumento de transacción bancaria frente a otros servicios del banco, llegando a crecer a un nivel total de 370,000 Libras Peruanas para fines de la década de 1920, es decir se multiplicó en cinco su emisión inicial. Sin embargo, desde 1927 el Estado peruano promocionaría la formación de una institución central que monopolizará el crédito del mercado hipotecario. (Ver Gráfico 1)

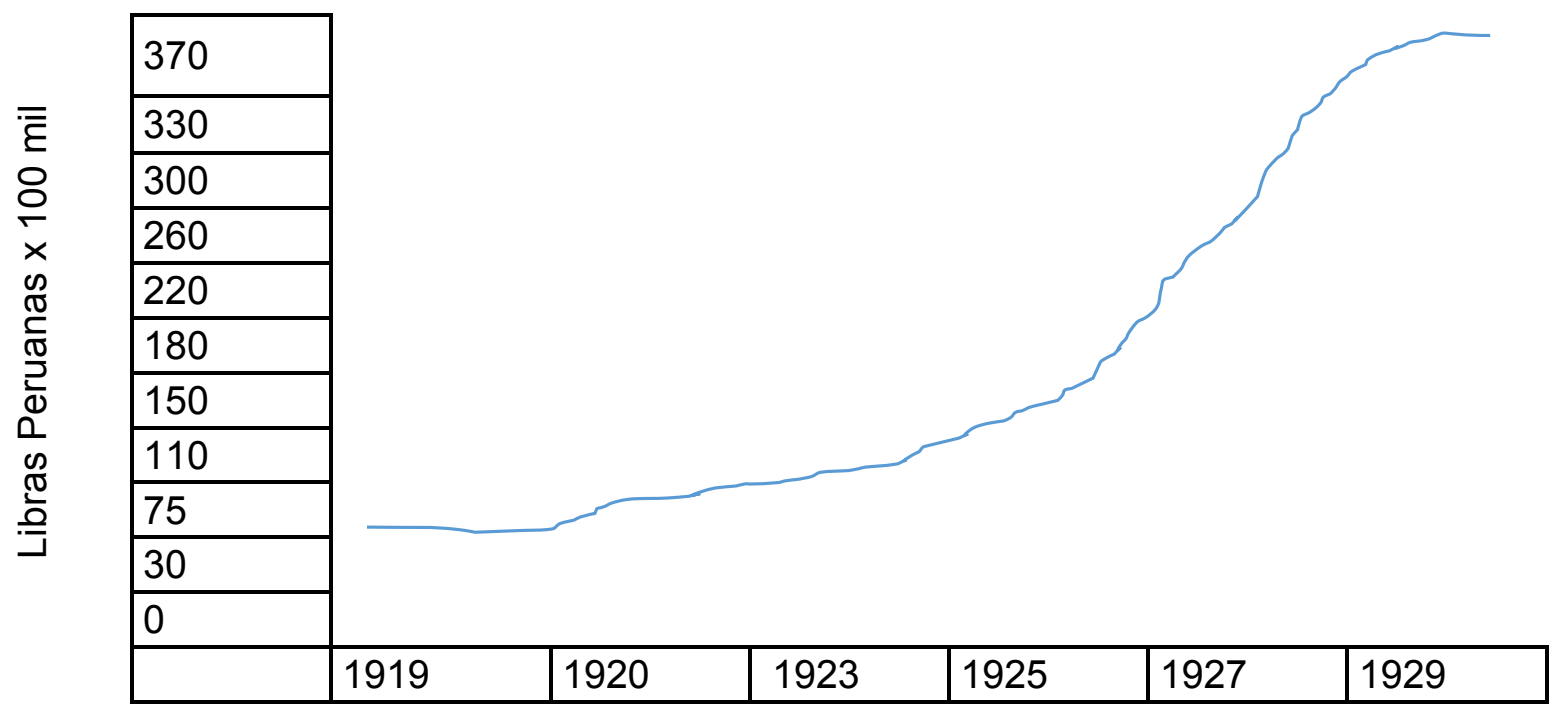

Gráfico 1. Emisión del crédito agrícola entre 1919-1930

(Extracto Estadístico, 1929-1933, Elaboración del autor)

No obstante desde 1928 la convulsión financiera golpearía la estructura de los créditos del Banco Perú y Londres a través de muchos retiros de depósitos, además de la expansión de fuertes activos destinados a los créditos agrícolas, ello inició un proceso de desprestigio de la solidez del banco.

Asimismo, el Banco Italiano su principal competidor en el mercado bancario nacional, mantuvo su capital extranjero, lo que permitió proveer de crédito a comerciantes y clientes que dirigen su negocio hacia la demanda urbana. Con lo cual el Banco Italiano no fue afectado directamente con las variaciones de las ganancias y pérdidas de los exportadores. En este sentido el Banco Perú y Londres había ido perdiendo progresivamente esta confianza al otorgar privilegios a directores o clientes favoritos. (Ver Gráfico 2).

Además en 1928 se promulgaron las leyes 4639 y 4807, que impusieron a los bancos extranjeros y a los nacionales la obligación de mantener un capital mínimo de 200,000 Libras 
Peruanas, con la finalidad de mantener un fondo elevado, así como también la prohibición de reducir el capital.

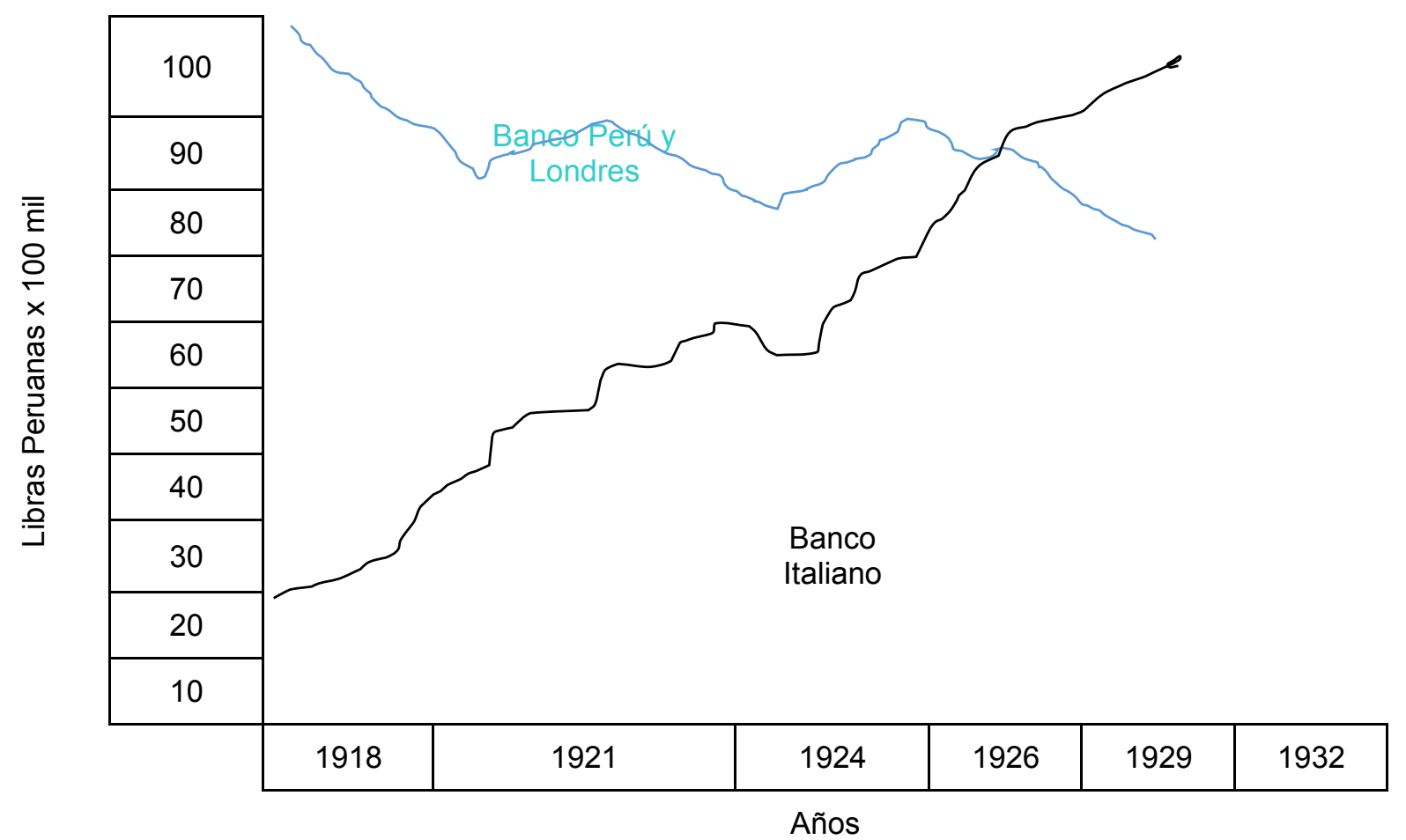

Gráfico 2. Curva de activos del Banco Perú y Londres y del Banco Italiano de 1918-1932

(Extracto Estadístico, Balance de bancos; apéndice B.)

En 1928 el Banco Perú y Londres va a reportar las primeras convulsiones económicas sobre las posesiones agrícolas iniciando el colapso de activos financieros en la ciudad de Lima, por ejemplo: el fundo «San Juan» del valle de Surco, que según contrato estaría en posesión de la administración Jorge Badani y la firma Ayulo por 10 años, con una renta de 80,000 Libras peruanas, sin embargo al año siguiente de trabajar el fundo iniciaron los embates de las fluctuaciones de los precios que hicieron impagables la posesión. Por lo tanto en diciembre de 1928 los arrendatarios del fundo «San Juan» sustentaban la falta de pago en una carta enviada al Ministro de Hacienda en la cual se argumentaba:

No disponer de la cantidad de agua necesaria para irrigar las 225 hectáreas. El problema de la exigua cantidad del agua solo hacía posible el trabajo de 90 hectáreas con lo cual no se podia esperar una ganancia de 150,000 Libras Peruanas, llegando incluso a obtener pérdidas en el balance final de 1927 y del consiguiente incumplimiento del pago al Banco Perú y Londres. A lo cual el Ministerio de Hacienda ordenó por Resolución Ministerial del 22 de agosto de 1929, la rectificación del contrato con el fundo «San Juan», es decir se refinanciaron los pagos por periodos temporales y estacionales con la finalidad de no declararse en quiebra, pudiendo asi frenar parte del desarrollo productivo de la zona sur de Lima. El acuerdo estipulaba el pago anual de 60,000 Libras Peruanas de manera anual (Banco Perú y Londres, 1928, legajo $\left.N^{\circ} 1590,278-280\right)$ 


\section{III.La convulsión financiera en el Perú de 1925-1930}

Dos acontecimientos marcan los últimos años de la década del veinte y el fin de otra prosperidad falaz. El primero es la oposición liderada por el Banco Perú y Londres a los proyectos de regulación gubernamental y a la dependencia económica, traducido en la obtención de deuda externa de la Guaranty Trust y The Foundation Company para los préstamos en obras urbanísticas. Esta intervención extranjera sienta la dependencia financiera con los Estados Unidos.

El segundo acontecimiento es el descenso en los precios internacionales de algodón y azúcar. Además del contexto climático del fenómeno natural de marzo de 1925 en la costa norte peruana, y la capacidad de respuesta del crédito para la agricultura del Banco Perú y Londres, ante estos acontecimientos la reacción del banco fue la de no recortar el crédito a los agroexportadores manteniéndose en igual proporción como se había venido desarrollando De esta manera, el banco asumía riesgos mayores en su afán de monopolizar las transacciones de los agroexportadores. Después del fenómeno natural de marzo de 1925 se va a comenzar a acercar la curva de préstamos con la curva de depósitos, obteniendo para finales de la década del veinte un estado de moratoria que coincidió con la crisis mundial de 1929 (Thorp y Bertram; 1985).

Por lo tanto tenemos que en el cuadro 1, se puede observar el constante crecimiento de los depósitos que van a ser colocados en cuentas corrientes es decir préstamos o créditos que los bancos van transferir a los clientes, en la cual el Banco Perú y Londres tiene hasta 1927 el liderazgo de este tipo de transacciones con un 33\% del total de bancos que otorgan crédito, manteniendo así regular competencia con el Banco Italiano.

Cuadro 1.

Evolución en porcentaje de la salida de activos destinado a créditos

\begin{tabular}{|c|c|c|c|c|c|}
\hline \multirow{2}{*}{ Nombre del Banco } & \multicolumn{5}{|c|}{ En cuenta corriente y depósitos } \\
\hline & $1927 \%$ & $1926 \%$ & $1925 \%$ & $1924 \%$ & $1923 \%$ \\
\hline Perú y Londres & 33.4 & 31.7 & 32 & 36 & 35 \\
\hline Italiano & 30.7 & 30.8 & 32 & 34 & 34 \\
\hline Internacional & 32.9 & 26.1 & 30 & 37 & 34 \\
\hline Popular & 23.3 & 25.2 & 23 & 27 & 29 \\
\hline Royal Bank of Canadá & 20.1 & 20.1 & 18 & 15 & 10 \\
\hline Anglo Sud Americano & 21.6 & 21 & 23 & 29 & 28 \\
\hline National City Bank & 18.5 & 22.3 & 25 & 27 & 24 \\
\hline Commercial Bank of Iquitos & 4.6 & 13.2 & 9 & 6 & ..... \\
\hline Promedios & 24.9 & 26.3 & 26.3 & 28.2 & 29 \\
\hline
\end{tabular}

(Inspección fiscal de bancos, Anexos; 1927)

Sin embargo en 1927, también se va a registrar el menor promedio total entre los cinco últimos años, con una caída en referencia al año anterior, que representa la caída de las colocaciones para los préstamos en especial para la agricultura. Con lo cual el Banco Perú y Londres va a registrar sus préstamos en un sentido constante, no siendo afectado por las externalidades del mercado internacional o de las inundaciones del fenómeno del niño en 1925.

En el cuadro 2, observamos la desaceleración en depósitos de ahorros por parte del Banco Perú y Londres. En comparación con las tres primeras instituciones que encabezan el total de las secciones de ahorro; se nota que la Caja de Ahorros de Lima inicia un proceso de crecimiento que 
va a liderar en los siguientes años, de igual manera el Banco Italiano va a registrar un escenario ventajoso al tener casi la misma proporción en ahorros que la caja de depósitos de Lima ya que de esta manera podrá balancear sus ingresos con los créditos otorgados al rubro de bienes y servicios. Pero esta fuga de capitales de las secciones de ahorro va a coincidir con el contexto de mayor facilidad para el otorgamiento de créditos. Sin embargo la reducción de su liquidez se va a sustentar en el origen de la especulación de las imposiciones de ahorros y de inversión sobre la Ley N. ${ }^{\circ} 5854$ que en su art ${ }^{\circ}$. 9, menciona:

Los bancos podrán dar el cincuenta por ciento (50\%) de los fondos procedentes del ahorro, a la inversión segura que estime conveniente, debiendo invertir precisamente el otro cincuenta por ciento (50\%) en cédula hipotecaria o bonos agrícolas. Dichos fondos, son preferentes a cualquiera otra imposición o acreencia, excepción el privilegio de que goza el banco de reserva del Perú.

Cuadro 2.

Cantidad de depósitos en ahorros y en porcentajes en 1927

\begin{tabular}{|l|c|c|}
\hline Instituciones & Libras Peruanas & Porcentaje \\
\hline Caja de ahorro de Lima & $6{ }^{`} 796,030$ & $34 \%$ \\
\hline Banco Perú y Londres & $5 ` 164.610$ & $26 \%$ \\
\hline Banco Italiano & $66^{`} 742,630$ & $34 \%$ \\
\hline Banco Internacional & 522,790 & $2 \%$ \\
\hline Banco Popular & 141,370 & $1 \%$ \\
\hline Total & $20^{\prime} 029,830$ & $100 \%$ \\
\hline
\end{tabular}

(Camprubí, 1968, p.127)

Posteriormente con la Ley N. ${ }^{\circ} 6161$ de 1928 se va a disponer la extensión de los fondos provenientes del ahorro, debiendo invertir en un $50 \%$ en todo lo detallado por el artículo $9^{\circ}$ de la Ley N. ${ }^{\circ}$ 5854; más la compra de acciones del Banco de Reserva del Perú. Con lo cual se intenta fortalecer a las entidades gubernamentales recaudadoras de activo financiero corriente ya que en esos años las instituciones están en un proceso de maduración de sus fines y van a necesitar de activos nacionales para cumplir con su propósito de creación.

Sin embargo la economía nacional en ese contexto iniciaba un proceso de creciente déficit fiscal, a pesar que los ingresos fiscales registraron índices de $8,3 \%$ por año en relación al periodo 1922-1928, al tiempo que el gasto público se incrementaba a una tasa promedio anual de 9,3\%, por lo tanto en el periodo de esos seis años el gobierno incurrió varias veces en déficit fiscal lo cual fue financiado con mayor endeudamiento externo teniendo como resultado la cantidad de aproximadamente 300 millones de Libras Peruanas al término de la década y siendo solamente en 1920 la cantidad de 81 millones de Libras Peruanas.

En 1929, el constante uso de préstamos estadounidenses por parte del gobierno peruano, bloqueó la posibilidad de escoger entre ofertas de préstamos más dinámicas. Además que los agroexportadores ligados a la actividad financiera rechazaron las medidas de estabilización monetaria patrocinada por financistas norteamericanos (Arrús, 1931, p.67).

La desvalorización de la Libra Peruana obedeció el transcurso final de los últimos años de la década que había sido originada fundamentalmente por la situación financiera, la cual el gobierno peruano llegó a reconocer explícitamente mediante la alteración de la paridad de la Libra Peruana en $\$ 4.00$ dólares en 1930. La nueva paridad responde a la necesidad del valor económico de la moneda y del tipo de cambio en el mercado internacional el cual no estuvo en 
equilibrio con esa arbitraria paridad sostenida artificialmente en los dos años anteriores en la economía local. Este tipo de estabilización responde al oscilante tipo de cambio que no reunía requisitos para el otorgamiento de préstamos de los acreedores al gobierno.

\section{La liquidación del Banco Perú y Londres}

El Banco Perú y Londres va a ser declarado en liquidación a finales de la década de 1920 sin embargo las razones para llegar a su cierre tiene múltiples aristas que van desde el cambio de pensamiento de una teoría clásica liberal a una teoría intervencionista asentada en el keynesianismo. Del mismo modo cabe mencionar las razones climáticas que van desde plagas en los campos algodoneros en los Estados Unidos hasta el fenómeno climático de 1925 y 1926 en la costa norte peruana pasando por un descenso en los precios a los productos de exportación de azúcar y algodón, por lo cual revisaremos estas aristas que concluyen en la liquidación del banco más prominente de la república aristocrática.

En cuanto a la supervisión del sistema financiero peruano, se va a reforzar la Inspección Fiscal de Bancos en 1921, a través de la aplicación de decretos supremos que van a prohibir la fuga de capitales con destino al extranjero debido a las circunstancias anormales del dinero y a la escasez del dinero circulante. Al año siguiente «la Inspección Fiscal de Bancos va a quedar adscrita al Banco de Reserva del Perú, por lo tanto se va a acentuar la intervención del Estado peruano como regulador y supervisor de las actividades bancarias mediante las leyes N. 4639 y 4807 de 1923; en la cual se va a imponer un capital mínimo de 200,000 Libras Peruanas en las instituciones bancarias, además de la prohibición de reducir el capital. Posteriormente se dictará la Ley N. 6161 de 1928 referida a la inversión obligatoria del 50\% de los depósitos de ahorro en bonos y créditos agrícolas, así como también a la participación en acciones del Banco de Reserva del Perú y de la Caja de Depósitos y Consignaciones» (Campubrí, 1968, p. 112).

En el contexto de la caída en el valor de las exportaciones, el sistema financiero peruano atravesará graves problemas en la estructura financiera y en la especialización del crédito agrícola. Hasta ese entonces el Banco Perú y Londres había invertido en emisiones especulativas como las empresas eléctricas, la compañía de vapores, la compañía recaudadora de impuestos y en la adquisición de los activos dejados por el Credit Foncier Peruvien, de la cual se habían colocado fondos de capital para el crédito agrícola.

Sin embargo, la gerencia del Banco Perú y Londres había sido incapaz de prever que los individuos e instituciones convierten su dinero en la moneda que le dé mayor liquidez, que pudiera ser el oro o el dólar, ocasionando de esta manera la caída en el precio de los valores y por lo tanto la restricción en el crédito. Aún más «el crédito externo se paralizó debido al colapso de la economía de Londres y de la mayor inflación de toda Europa en Francia, por lo tanto; el Anglo South American Bank y la Sociètè Gènerale comenzaron a cancelar las líneas de crédito emitidas al Banco Perú y Londres. Sin embrago, lo más peligroso para el banco sería la crisis fiscal; que se registró en una fuerte declinación de los ingresos, ya que el otorgamiento de préstamos al Estado y la participación en la compañía recaudadora de impuestos fueron transacciones de mayor actividad para el Banco Perú y Londres» (Quiroz, 1989, p. 253).

Ante este escenario el Credit Foncier Peruvien de capital francés e inglés decidió su salida de la sección hipotecaria del Banco Perú y Londres por la exigencia de las conexiones parisenses al incremento de la tasa de interés para préstamos crediticios, esta medida sería una de las principales razones de la subsecuente volatilidad de los activos financieros al verse desprovisto 
de capital financiero. Ya que en los periodos 1907 a 1917 la sección hipotecaria del Banco Perú y Londres tuvo una estabilidad a pesar del contexto de la guerra mundial que había traído una declinación del negocio hipotecario en el sistema financiero en general. De manera gradual en la década de 1920, el Banco Perú y Londres perdió supremacía sobre el mercado crediticio frente al Banco Italiano y posteriormente frente al Banco Central Hipotecario del Perú.

Atrás quedarían la exclusividad de los créditos e hipotecas a las personas cercanas al Banco Perú y Londres, como por ejemplo «La Sociedad Agrícola Paramonga, dirigida por Francisco Mendoza y Barreda, que en el contexto de la obtención del crédito agrícola va a ser director del Banco Perú y Londres, con lo cual va a realizar pagos de hipotecas por 280 mil Libras Peruanas que fueron adquiridas por el Banco Alemán» (Banco Perú y Londres, Directorio, N. ${ }^{\circ}$ 1540, vol.14, 18 enero de 1925).

De igual manera la retracción del crédito agrícola dejaría sin sustento financiero a aquellos clientes principales que habían basado su arraigo oligarca mediante la expansión del crédito agrícola, como por ejemplo:

El terrateniente Miguel Echenique que en julio de 1926 va a adquirir préstamos hipotecarios sobre las propiedades del fundo Jesús de Valle, por una cantidad de 65 mil Libras Peruanas; además la Sociedad Agrícola Huamaya fusionada con el ingenio central de Huaura, que en noviembre de 1926 va a registrar una cantidad en crédito agrícola de 41 mil Libras Peruanas; también La Familia Ganoza de la costa norte peruana, que en marzo de 1928 van a registrar una transacción de 48,886 Libras Peruanas; de igual modo la compañía agrícola e industrial de cañete que pertenecía al presidente Augusto B. Leguía va a registrar en marzo de 1928 un crédito por 200 mil Libras Peruanas, y por último la Sociedad Herbay Alto en noviembre de 1929 van a solicitar un crédito por 55 mil Libras Peruanas (Banco Perú y Londres, Directorio; $N^{o} 1540$, vol.14, 18 enero de 1925).

Cabe mencionar, que no solamente el activo financiero de la sección hipotecaria del Banco Perú y Londres cubrió su liquidez con capital extranjero sino mediante el cobro de viejas deudas, como por ejemplo: la fiscalización de moratorias llevadas a cabo por la Inspección Fiscal de Bancos enviando cartas al Banco Perú y Londres avisando de la peligrosa situación en torno a las deudas atrasadas por parte de la firma Ayulo \& Cía., en este caso en 1925 la firma Ayulo se va a ver obligada a transferir los pagos por créditos hipotecarios por 75 mil Libras Peruanas.

Las promesas de pagos que debían afrontar bordeaban en 1925 la cantidad de 80,000 Libras Peruanas y 160 mil Francos. A pesar de que la Cía. estaba representada en la dirección del Banco Perú y Londres por Alfredo Ayulo, gerente de la Cía., el cobro de la deuda sería de un total de 280 mil Libras Peruanas. Cifra que representaba el 50\% del total de la sección hipotecaria y préstamos del Banco Perú y Londres (Banco Perú y Londres; Directorio; $N^{o}$ 1559, vol.14, p.261, abril de 1925).

Las dificultades de la tasa de retorno de los créditos agrícolas van a iniciarse en aquellos grandes préstamos de clientes que tenían una doble participación en la escena nacional, es decir con el Banco Perú y Londres y con el gobierno del Presidente Augusto B. Leguía, como por ejemplo:

Los préstamos a la hacienda Roma de propiedad de la familia Larco; los cuales van a enfrentar los embates de la contracción de los activos financieros en 1926, que comenzaría a causar preocupación por el sobregiro de su cuenta corriente en el banco por 30,565 libras peruanas, la mayor cuenta en depósitos pasivos. En el transcurso de 1926 en adelante la 
hacienda Roma va a incurrir en dificultades financieras y se van a ver obligados a poner en venta la hacienda Roma a la firma alemana Gildemeister por 1 300,000 Libras Peruanas en agosto de 1927. En síntesis si no se hubiera realizado la venta de la hacienda Roma; el Banco Perú y Londres no hubiera podido proveer más crédito a la firma de la familia Larco ya que las peligrosas circunstancias de descenso en los activos afectaban la estructura financiera y el sistema bancario en general (Banco Perú y Londres, Directorio; $N^{o} 1696$, vol.16, p.8, mayo de 1927).

En 1926, la Inspección Fiscal de Bancos venía estudiando los activos provenientes del ahorro, especialmente a los que respecta la garantía e inversión, si bien es cierto que existía una Ley de ahorros que data de 1901, esta en la práctica resultaba letra muerta ante las notificaciones enviadas a las instituciones bancarias; ya que no se podía adaptar las viejas normas a un contexto muy distinto en la cual se elaboró, por lo tanto el gobierno promovió una nueva ley en materia de ahorro, modificando y accionando nuevos dispositivos conforme a la estructura financiera. Esta ley fue promulgada en julio de 1927 con el № 5854; la novedad de la ley es que se debería invertir el 50\% en cedulas hipotecarias y en créditos agrícolas. Dejando atrás la estructura de la antigua Ley promulgada en 1901, la cual consistía en la inversión de dos tipos: la primera en propiedades raíces, sustentadas en bonos hipotecarios y la segunda en títulos de deuda nacional. (Inspección Fiscal de Bancos; $6^{\circ}$ Informe, 1926).

La nueva Ley del Ahorro va a promulgarse como respuesta a los acontecimientos del fenómeno climatológico que inundó la costa norte en 1926, que tenía a la economía nacional en serios déficit fiscales, además de coincidir con el inicio del ritmo declinante del tipo de cambio, que hacía que la inflación aumente sobre la deuda externa.

La representación de la deuda externa estuvo en mayor participación con las instituciones financieras norteamericanas como el Seligman \& Co., y la National City Bank, que en 1927 van a suspender la entrega de prestamos al gobierno de Augusto B. Leguía. «En respuesta y por consejo del Banco de Reserva del Perú, el gobierno va a comenzar a despojar de los sectores estratégicos al Banco Perú y Londres; para tal efecto se va a promover la instalación del Banco Central Hipotecario para realizar obras urbanas con constructoras norteamericanas»». Lo trascendente de este hecho es que el estado comienza a recortar participación y protagonismo a las instituciones privadas desplazándolos del mercado de crédito hipotecario (Banco Perú y Londres, Directorio; $\mathrm{N}^{\mathrm{o}} 1734$, vol.16, p. 80 , febrero de 1928).

Este tipo de política de recorte y de imposición de funciones al Banco Perú y Londres ya se había iniciado, en 1925. Con lo cual el banco se opuso a la modificación de la Ley hipotecaria de 1889. En esta modificación el Estado ordenaba la expansión de los préstamos a terrenos sin cultivar o producir, dejando atrás su exclusividad en el préstamo. Al final de la década, en su afán intervencionista el gobierno de Augusto B. Leguía modificará los estatutos del Banco Central Hipotecario con la finalidad de incluir el crédito agrícola como función predominante; que en la década del veinte propició el boom de la agro exportación. Por lo tanto la institución como especialista en créditos y préstamos va a recaer en el Banco Central Hipotecario y Agrícola del Perú, es decir el antecedente del Banco Agrícola del Perú.

Aparte de los cambios en la política intervencionista, mediante la creación de instituciones de fomento, el gobierno de Augusto B. Leguía en 1929 -en un contexto de convulsión económicava a implementar un paquete de medidas para enfrentar la crisis. Proyectó subir la tasa de interés y restringir el crédito en las instituciones privadas con el fin de estabilizar el tipo de cambio y detener la inflación. Sin embargo el Banco Perú y Londres que aún mantenía el liderazgo de 
la banca, más por política que por su capacidad económica, argumentaba la oposición de estas medidas ya que a la subida de la tasa de interés y el cierre de crédito solo traerían dificultades para la recuperación de sus activos además que la banca especialmente el Banco Perú y Londres venía experimentando problemas de liquidez de sus activos desde 1926. Con lo cual los agroexportadores que disponían de crédito apoyaron las quejas del Banco Perú y Londres, sin embargo

el paquete de medidas para enfrentar la inflación fueron aplicados en noviembre de 1929 por lo cual la tasa de interés se incrementó de 8 a 10\%, esto significó que el Banco Perú y Londres inició una etapa irremediablemente de caída en sus recursos, el banco para este año no fue declarado en bancarrota ya que aún tenía contactos con la esfera cercana al gobierno de Augusto B. Leguía, pero ya se había realizado el cierre de sus actividades. (Banco Perú y Londres; Directorio; $N^{o} 1825$, vol.16, p. 75, noviembre de 1929).

Es decir la creación de instituciones de fomento como el Banco Central Hipotecario del Perú y del Crédito Agrícola, además de un paquete de medidas sobre el tipo de cambio y de la estabilización monetaria con el fin de calificar para los préstamos en el extranjero aunado con los estragos de unos de los mayores fenómenos climáticos del siglo XX, propiciaron la aceleración de la liquidación del Banco Perú y Londres, a continuación explicaremos el proceso de liquidación mediante leyes y el contexto de la crisis mundial de 1929.

Con la Ley N. ${ }^{\circ} 6126$ de 1929 que modificó los estatutos del Banco Central Hipotecario, también se dictó normas para efectuar préstamos hipotecarios de pagos graduales a una razón de largo plazo. En referencia a esta norma la temporalidad de los créditos fue algo que favoreció su aceptación ya que los bancos privados solo otorgaban crédito a corto plazo recortando así el desarrollo económico y limitando las importaciones. La modificación en este sentido también permitía una apertura de régimen de privilegios y de cédulas hipotecarias. Además de lo imperativo de la Ley $\mathrm{N} .{ }^{\circ} 6126$ que va a patrocinar y promover liquidaciones abiertas de las instituciones que hasta ese momento venían realizando labores en sus secciones hipotecarias.

Paulatinamente estas instituciones como el Banco Perú y Londres, Banco Italiano, Banco Internacional y el Banco Popular van a ser absorbidos -las secciones hipotecarias- por el Banco Central Hipotecario del Perú. El balance de las operaciones de préstamos y créditos por parte de la Caja de Ahorro de Lima y de los bancos comerciales al 31 de diciembre registra la siguiente información:

Cuadro 3.

Balance de préstamos y cédulas crediticias en 1929

\begin{tabular}{|l|c|c|}
\hline \multicolumn{1}{|c|}{ Instituciones } & Préstamos S/. & Cédulas S/. \\
\hline Caja de Ahorros de Lima & $3^{`} 855,000$ & $3^{`} 844,000$ \\
\hline Banco Perú y Londres & $12^{`} 081,000$ & $11^{`} 786,000$ \\
\hline Banco Internacional & $1^{\prime} 758,000$ & $1^{\prime} 744,000$ \\
\hline Banco Popular & $22^{`} 199,000$ & $2^{\prime} 192,000$ \\
\hline Banco Italiano & $21^{\prime} 251,000$ & $21^{`} 217,000$ \\
\hline
\end{tabular}

(Camprubí; 1968, p.117)

La confrontación de estas cifras revela una evolución regular y ascendente en los préstamos, sin embargo para el Banco Perú y Londres las cifras representan un trazo irregular y en caída, ya que para captar más activo corriente el banco ofreció a su clientela una forma de depósitos especiales con determinadas ventajas aunque sin mucha garantía, ocasionando que sus clientes 
transfieran sus depósitos y sus ahorros. Sin embargo, después de la liquidación, el banco enfrentaría el estado de moratoria que intensificó su cierre de actividades (Inspección Fiscal de Bancos; Informes ; 1928).

El estado de moratoria inició debido a la especulación en torno a los activos que el banco anunciaba a los diarios, la situación descrita era de un progreso satisfactorio en relación al cierre del Balance general de 1928 (El financista, N. 334, febrero de 1930). Por lo cual distribuyeron utilidades a sus accionistas de más del $10 \%$, en referencia al cierre del año anterior a fin de reforzar la idea de una sólida liquidez a los ahorristas e inversionistas. Pero en realidad sus reservas en los bancos extranjeros fueron cayendo en 30\% del total en 1928, llegando a tener en 1929 solo el $10 \%$.

En este contexto las instituciones norteamericanas ofrecieron consultorias financieras acompañadas de ofertas de compra lo cual rechazaron. Por ejemplo el Chase National Bank envió ofertas de compra desde 1927 pero fueron rechazadas por los términos y condiciones, ya que se quería mantener el Statu quo de la dirigencia nacional del banco que en su mayoría pertenecía al sector agroexportador a fin de disponer de créditos, y contrarrestar la pérdida de valor de las exportaciones (Quiroz, 1989, p.296).

El rechazo de las ofertas de compra de la banca extranjera se realizó por conveniencia para los deudores de préstamos hipotecarios y de crédito agrícola, ya que un proceso de liquidación nacional sería menos riesgoso que llevado por las instituciones norteamericanas, en este sentido la elite local actuó de manera anticipada. Conforme a las memorias del Banco Perú y Londres;

los directores del banco no estuvieron dispuestos a forzar la cancelación de las deudas, ya que hubiera significado poner a varios agroexportadores en quiebra, además de obtener pocos pagos al reembolso total, sin embargo la conducta de los agroexportadores fue la de finiquitar las deudas con un pago ascendente a los 3 millones de soles en 1930, para poder acelerar la culminación del estado de moratoria que se había incrementado casi en la misma proporción al pago realizado (Banco Perú y Londres, Memorias del consejo de administración a la junta general de accionistas, 1931, p.4).

Al tiempo que se realizaban estos pagos, los bancos norteamericanos como el Irving Bank, Columbia Trust, Chase National Bank y el City Bank comenzaron a apropiarse de los fondos del banco, llegando incluso a querer realizar el cobro por deudas en los préstamos del crédito hipotecario y del crédito agrícola; sin embargo estos pasivos financieros ya estaban cancelados y la moratoria estaba en proceso de ser pagada con lo cual no hubo mayor interferencia extranjera en la liquidación del Banco Perú y Londres.

Sobre el rumbo de las liquidaciones bancarias como efecto de la crisis mundial de 1929, la Superintendencia de Bancos del Perú señala a cuatro bancos en proceso de liquidación: el Banco Perú y Londres, el Banco de Tacna, la sección hipotecaria de la Caja de Ahorros y la Sociedad de Beneficencia Pública del Callao, especialmente el Banco Perú y Londres merece predominante atención por la magnitud de su cobertura.

En 1932 la memoria de la Superintendencia de Bancos del Perú sintetiza la labor del año en ejercicio sobre la liquidación del Banco Perú y Londres y describe de esta manera el proceso:

Las importantes empresas subsidiarias del banco han quedado reorganizadas en completo acuerdo con los demás acreedores y accionistas, y están manejadas por personal idóneo. Habiéndose salvado a algunas de ellas de la quiebra o de una liquidación violenta; por lo cual se han tomado las medidas esenciales de seguridad para resguardar los derechos del banco frente a sus deudores, 
además se está terminando de pagar la integridad de los créditos preferenciales derivados de la imposición de la sección de ahorros, cuyo monto total ascendía a 12'000,000 de soles, siendo pagados en gran parte con los productos de la liquidación del activo y en parte con el producto del préstamo obtenido por el Banco Central de Reserva del Perú. (Superintendencia de Bancos, Estadística Bancaria de 1932, Lima, 1933, p. 7).

Además con la Ley N. ${ }^{\circ} 7582$ es que se autoriza al Banco Central de Reserva del Perú que realice pagos directos a favor de la liquidación del Banco Perú y Londres por 6’000,000 de soles a un año de plazo, con la finalidad de apresurar la liquidación. Este préstamo se aplicó al pago de las imposiciones de ahorros en las secciones de depósitos, cuya preferencia habría sido reconocida por la ejecutoria suprema del 28 de setiembre de 1931.

En el artículo $3^{\circ}$ de la mencionada ley, se establece que el Banco Central de Reserva del Perú tendrá preferencia absoluta en la liquidación del Banco Perú y Londres, por razón de este préstamo, excepto de aquellos que gocen de prenda mercantil o hipoteca registrada, así como también el derecho de vender los valores dados en prenda, previo aviso a la Superintendencia de Bancos del Perú, aplicando de esta manera el importe a la amortización del préstamo.

Y en el artículo $5^{\circ}$ de dicha norma, manifiesta el estricto uso de los pagos realizados de la liquidación bancaria para acabar con el estado de moratoria del Banco Perú y Londres. Con lo cual se demuestra la respuesta del Estado peruano por facilitar la liquidación bancaria con la finalidad de aperturar políticas de fomento para reactivar la economía como fue el Banco Agrícola del Perú.

\section{Conclusiones}

En el presente artículo de investigación se ha descrito las posibles causas que originaron la liquidación del Banco Perú y Londres, partiendo de una estructura histórica mayor como fue el fenómeno climático de 1925 y 1926 que agudizó la crisis de las cosechas de azúcar y algodón en la costa norte peruana, de lo cual se demuestra que el Banco Perú y Londres continuó con la especialización del crédito agrícola; ya que el banco tenía en su dirección a agroexportadores dedicados al azúcar y al algodón entre otras materias primas, continuando así los préstamos para la reconstrucción de lo devastado por las inundaciones.

Hemos profundizado en el accionar político y el contexto económico anterior a la crisis mundial de 1929; y luego, descrito el boom de las agroexportaciones en los primeros cinco años de la década de 1920 y posteriormente su caída en el valor de los precios por medio de una contracción en el consumo en el mercado extranjero, siendo este último la causante de la caída de Wall Street en 1929. Además se ha demostrado con fuentes primarias el cambio de paradigma de una política liberal a una política intervencionista representada por el Banco Central Hipotecario y Agrícola en la segunda parte de la década de 1920, siendo esta institución requisito para los préstamos venidos del extranjero además de restarle protagonismo al Banco Perú y Londres por la salida de su capital extranjero y de la pérdida de la compañía recaudadora de impuestos.

Y en una capa coyuntural de la historia de la liquidación del Banco Perú y Londres el artículo de investigación analiza la legislación cambiante en torno al sistema financiero peruano y su repercusión en la estabilización de la moneda, que después sería reformada por la Misión Kemmerer. Además en la última parte del artículo se demuestra que la liquidación del Banco Perú y Londres fue un hecho anticipado por la dirección nacional y de rápido cierre de actividades con la finalidad de que la participación no sea también de los bancos garantes en los Estados 
Unidos. Ya en la década de 1930 el proceso de liquidación del banco va a estar adscrita al Banco Central de Reserva del Perú.

\section{FONDOS DOCUMENTALES:}

\section{- Banco Perú y Londres}

1. Archivo General de la Nación. (1912). Banco Perú y Londres, Directorio, № 1540, vol.6, Enero.

2. Archivo General de la Nación (1914) Banco Perú y Londres; Directorio; №1015, Vol.8, Noviembre.

3. Archivo General de la Nación (1917) Banco Perú y Londres; Directorio; No 1149, Vol.9, Mayo.

4. Archivo General de la Nación (1918) Banco Perú y Londres; Comité de Directorio; Vol.1.

5. Archivo General de la Nación (1921) Banco Perú y Londres; Accionistas; Vol.3.

6. Archivo General de la Nación (1921) Perú y Londres; Directorio; № 1352, vol.12, Mayo.

7. Archivo General de la Nación (1922) Banco Perú y Londres; Directorio; № 1432, Vol.13, Noviembre.

8. Archivo General de la Nación (1923) Banco Perú y Londres: Directorio; No 1457, Vol. 13, 9 de Agosto de 1923.

9. Archivo General de la Nación. (1925). Banco Perú y Londres, Directorio, N 1540, vol.14, Enero.

10. Archivo General de la Nación (1925). Banco Perú y Londres, Directorio, No 1559, vol.14, Abril.

11. Archivo General de la Nación (1927). Banco Perú y Londres, Directorio, № 1696, vol.16, Mayo.

12. Archivo General de la Nación (1928). Banco Perú y Londres, Directorio, № 1734, vol.16, Febrero.

13. Archivo General de la Nación (1928) Perú y Londres; Legajos; No 1590, O.L 861.

14. Archivo General de la Nación (1929). Banco Perú y Londres, Directorio, № 1825, vol.16, Noviembre.

\section{- Informe Fiscal de Bancos}
a. Archivo General de la Nación (1913) Inspección Fiscal de Bancos; Informe del año 1913, Lima; 1913.
b. Archivo General de la Nación (1927). Inspección Fiscal de Bancos, Informe, O.L- 869
c. Archivo General de la Nación (1928) Inspección Fiscal de Bancos, Estadísticos, N 1590.
d. Archivo General de la Nación (1929) Inspección Fiscal de Bancos, Sexto Informe, 1926-1929.

\section{- Otros Fondos}

I. Archivo General de la Nación (1930). El financista, No 334, Febrero.

II. Archivo General de la Nación (1931). Banco Perú y Londres, Memorias del concejo de administración a la Junta General de Accionistas, Lima: Imprenta Gil.

III. Banco Popular del Perú (190). Sección Hipotecaria, Imprenta Gil; Lima.

IV. Banco de Reserva del Perú; Legislaciones; Lima: Torres Aguirre, 1944.

V. Memoria de la Superintendencia de Bancos (1933). Estadística Bancaria de 1932, Lima; Imprenta Gil, S.A Calle de Zárate. 


\section{REFERENCIAS BIBLIOGRAFICAS}

1. Arrús, O. (1931). La Estabilización de Nuestra Moneda. Lima: Ed. El Comercio.

2. Camprubí, C. (1968). Un siglo al servicio del ahorro: 1868-1968. Lima: Sociedad de Beneficencia Pública.

3. Drinot P. y Knight A. (2016) “La Gran Depresión en América Latina”, Fondo de Cultura Económica

4. Goldsmith, Raymond (1969) "Financial Structure and Development" New Haven CT: Yale University Press.

5. Marichal, Carlos (2010) "Las Grandes Crisis Financieras; Una perspectiva global de 1873-2008", Debate.

6. Quiroz, A. (1989). Banqueros en Conflicto. Estructura Financiera y Economía Peruana, 1884-1930. Lima: Universidad del Pacifico.

7. Seminario, Bruno (2015) "El Desarrollo de la Economía Peruana en la era Moderna; precios, población, demanda y producción desde 1700", Lima: Universidad del Pacifico.

8. Thorp, R. \& Bertram, G. (Ed.). (1985). Perú: 1890-1977. Crecimiento y Políticas en una economía abierta. Lima: Mosca azul, Universidad del Pacifico y Fundación Ebert.

Presentado: 3 julio 2017

Aceptado: 6 febrero 2018

Publicado online: 11 julio 2018 